\title{
Distress financing in coping with out-of-pocket expenditure for maternity care in India
}

\author{
Shalem Balla, Md Illias Kanchan Sk, Mayanka Ambade and Babul Hossain
}

\begin{abstract}
Background: The cost of maternity care is seen as the barrier in utilizing maternity care, resulting in high maternal deaths. This study focuses on the distress financing and its coping mechanisms associated with maternity care expenditure in India so that corrective measures can be taken to reduce the burden of maternity care.

Methods: This study used the National Sample Survey (NSS) data conducted in 20,014-15 (71 st $^{\text {round }}$ of NSS) and 2017-18(75 th round of NSS). We define distress financing as use of formal borrowing, borrowing from friends or family or sale of asser to finance maternity care. Percentage of pregnant/delivered females using distress financing were calculated.. The present study also used multinomial logistic regression with $95 \%$ to understand the impact of socio-economic variables on distress financing and concentration index to measure the inequality in maternity care expenditure.
\end{abstract}

Results: This study found that the maternity care expenditure has decreased from the INR. 9379 in 2014-15 to INR. 7835 in 2017-18. The percentage of households using distress financing is higher among the poorest (13.2\%). Almost $14 \%$ of the SC households experience distress financing. Among EAG + A states, particularly in Madhya Pradesh and Uttarakhand, the percentage of households are which experience a high level of distress financing increased from 8.9 to 18.3 and 0.7 to 8.1 from 2014-15 to 2017-18 respectively. The study finds that more urban households (37\%) utilized insurance than rural households (26\%). Among EAG + A states, 67.9 percent of households were dependent upon household savings, and it was 63.6 percent in the non-EAG states. The households with a high burden of maternity care expenditure were at higher risk of borrowing money to finance the cost of maternity as compared to use of savings/income for the same (relative risk (RR) (R: 2.59; $P<0.01 ; 95 \% \mathrm{Cl}: 2.15-3.13)$. Mothers belonging to the SC caste were at significantly higher risk (RR: $1.43 ; P<0.1 ; 95 \% \mathrm{Cl}: 1.07-1.91$ ). of using borrowings as compared to the use of income/savings. Mothers with college education were $50 \%$ more likely to use health insurance as compared to those with primary education.

Conclusions: The study found that even though many programs for maternity care services are there, the maternity care expenditure, particularly the delivery care expenses, is very high in many states. The study recommends that India should increase subsidized maternity care facilities to decrease catastrophic maternity expenditure among households.

Keywords: Maternity care, Expenditure, Distress Financing, Coping Mechanism 


\section{Background}

The recent estimation shows even though there is a $45 \%$ decline in global maternal mortality from 1990, preventing maternal mortality has remained a vital challenge to health systems in developing countries [1]. Around 295,000 women still die during pregnancy and childbirth, and $94 \%$ of these deaths occur in developing countries due to maternal risk factors [1]. Dating back to the 1940s, the Maternal Mortality rate (MMR) in India was 2000/100000 live births. Today, after 70 years of independence, the MMR of India has dipped to $113 / 100000$ live births [2]. The majority of these deaths can be averted by providing proper and effective maternal care to pregnant women. A significant proportion of maternal deaths are preventable. The highest number of deaths in developing countries, including India, are due to complications like haemorrhage, eclampsia, and other avoidable causes [3]. Providing proper maternity care services could effectively reduce the number of maternal deaths $[4,5]$. The cost of maternity care is seen as an access barrier to utilizing maternity care, resulting in high maternal and neonatal deaths $[5,6]$. Therefore, it is a must need in countries like India to provide maternity care services free of cost. Total expenditure on health in India constitutes $3.6 \%$ of GDP, and out-of-pocket expense include $64.5 \%$ of the total health expenditure [7]. The high burden of maternal deaths and poor maternal outcomes are prognosis of low utilisation of quality health care. Studies have found a strong association between the high maternal care expenditure and low utilisation of maternal health care [8-11]. Hence, it is crucial to understand the context of high maternal care expenditure and quality of care.

The total expenditure of delivery care includes the cost for medicines and the cost for other expenses like the cost of doctor's fee, price on diagnostic tests, transportation, etc. $[9,10]$. Cost is a substantial reason for the availing of maternal care services in India. Studies have strongly suggested that a significant proportion of households are poor due to high out-of-pocket spending for health $[12,13]$. The poor often use their wage income to pay off the health care expenses, wherein the less poor meet them with their savings [14]. The cost of delivery care at institutions is five times higher than at home [15]. In lowincome countries, health care spending is met by direct payments, which makes them critically pervasive than the high, making them critically more pervasive than in high-income countries that use prepayment methods to finance [16]. Public facilties provide a viable solution to counter the high burden of maternity expenditure in private facilties. It has been found that there are direct and indirect expenses for maternal care where the direct expenditure for delivery care is lower than the indirect in public facilities whereas the direct costs for the same are less in private facilities than the indirect [17]. The study conducted by Mohanty, Kastor \& Anshul [18] showed that women going to public health facilities increased from $11 \%$ in 2004 to $31 \%$ by 2014 while in private had increased from 12 to $20 \%$ during the same period. However, India's public health facilities are regarded as low quality because of unavailability and absence of professionals, poor infrastructure and facilities, unavailability of drugs, and proper equipment. Because of these factors, many people prefer to go to private health facilities [19-21].

According to the permanent income hypothesis, families decide current consumption patterns by assuming future income $[22,23]$. If the maternity care expenditure is nominalised, households can spend from their household incomes or savings and if the households have insurances, then they will go for it. But if the maternity care expenditure is catastrophic, the families may choose to go for borrowings from banks and friends [24]. Even if the households can't afford to pay, they will forego assets by selling to meet the expenditure [24, 25].

It is well documented that the population faces the challenges of distress financing to cope with the high levels of maternity expenditure. Distress financing means using of borrowings or the sale of physical assets [26, 27]. Distress financing will be used when households don't have proper household savings, income, or insurances. Distress financing is limited to the poorer section of society as they have limited funding options and unavailability of economically valuable assets [28]. Previously, studies have mainly dealt with the households experiencing catastrophic maternity care expenditure $[15,17$, 29, 30]. But one should emphasise understanding how the families arrange this expenditure for maternity care. Therefore, this study focuses on the coping mechanisms and distress financing in India so that corrective measures to reduce the burden of maternity care and improve maternal health can be suggested.

Previously studies have looked into the cost of maternity and analyzed the impact of conditional cash transfer schemes such as JSY on the economic burden of maternity $[25,26,29,30]$. Studies have also looked into distress financing of institutional deliveries and maternity care. Also, studies do not provide bifurcation of costs by nature of expenditure i.e. delivery, medication, doctor consultation charges, transport etc. $[25,30]$. Further, in the light of recent developments such as introduction of PMMVY (Pradhan Mantri Matru Vandana Yojana), it is imperative to generate updated estimates of distress financing due to maternity expenditure and compare it with previous estimates to track any changes thereof. Therefore, this study also looks into the level and trends of distress financing 
due to maternity expenditure and its change between 2014 and 2018. Since 2014 is a pre PMMVY timeline, such comparison provides us with evidence to map the impact of the policy on distress financing. We also inverstigates expenditure patterns of maternity care and its coping mechanisms for the EAG + Assam, highly experiencing maternal mortality states and non-EAG states with comparatively low maternal mortality.

\section{Methods}

\section{Data source}

The present study utilized the two rounds of 71st and 75th Round National Sample Survey (NSS) on the theme 'Social consumption in India: Health to understand the household experiencing distress financing for delivery Care in India. The data from the 25th schedule of the 71st round and 75th round was used, which was completed in 2014-15 and 2017-18. The primary aim of the health survey was to collect necessary quantitative information on the health sector, the profile of ailments including their treatment, role of government and private facilities in providing healthcare, expenditure on medicines, expenditure on medical consultation and investigation, hospitalization, and expense of maternity and childbirth, etc.

The 71st round surveyed 65,932 households with 333,104 persons, and the 75th round covered a total of 1,13,823 families and 5,55,115 individuals across various States and Union Territories in India. The NSS uses a stratified two-stage design to sample census villages in the rural areas and the NSS urban frame survey blocks in the urban areas in the first stage, followed by a sampling of households in the second stage.

Data on the maternal care expenditures during the antenatal and postnatal period were collected from women aged 15-49 years who delivered their babies or were pregnant before 365 days of the survey. Information on delivery care expenditure was collected as expenses incurred during the last 365 days for in-patient medical care during childbirth. In all, 19,445 women reported to be pregnant in the 365 days before the survey; of the 14,462 women reported having a hospital birth during the reference period. So, to analyse pregnancy and maternity expenditure, we restrict our analysis to those 14,462 women who gave birth in a hospital setting in the 71 st round.

In all, 32,257 women were reported being pregnant in the 365 days before the survey; of them, 27,625 women were reported having a hospital birth during the reference period and alive after delivery, so we restricted our analysis to those 27,625 women who gave birth in a hospital setting in the 75th round.

\section{Description of the variables \\ Outcome variables: Maternity care expenditure}

Expenditure incurred during the last 365 days on prenatal care was considered as antenatal care expenditure. The cost incurred for the delivery as in-patient within the past 365 days was collected under separate heading. Here, the total expenses are the complete medical and non-medical expenses. Medical expenses include package, doctor's/surgeons fee, medicines, diagnostic charges, bed charges, and other costs. Along with this, transport and non-medical expenses are combined to give the total expenditures during delivery care. For postnatal care, expenditure was incurred during the last 365 days on postnatal care. The study has considered the women who have utilised the services in the past 365 days. So there are cases where women who were pregnant before one year and had delivery then but have taken PNC within the last 365 days. Correspondingly, women who were pregnant before 365 days but did not deliver but availed ANC in before last the year. The samples have been chosen based on this consideration. Assumably those who have availed ANC, have also taken PNC.

\section{Distress financing}

It is a condition where the household meets their expenditure by borrowing and/or selling any physical assets. In this study, distress financing is any financial source other than savings and insurance. A dichotomous variable was generated with 0 as not experiencing distress financing and 1 as facing distress financing.

\section{Control variable}

$\mathrm{EAG}+\mathrm{A}$ and non-EAG states were considered as the control variable in the study. This study used EAG + A (Empowered Action Group States and Assam) as one group and non-EAG (other states) as another group for comparison purposes. EAG +A states includes Uttar Pradesh, Rajasthan, Madhya Pradesh, Chhattisgarh, Odisha, Bihar, Jharkhand, Uttarakhand and Assam. Other than these, nine states are called non-EAG states.

\section{Independent variables}

The study used individual and household-level covariates. The basic covariates used in the analysis were the age of the mother (15-24, 25-34, 35-44 and 45 above), place of residence (rural/urban), social class (Scheduled Caste, Scheduled tribe, Others (Other backward Classes and others)), religion (Hindu, Muslim, and others), education (No literate, Literate without schooling, Primary, Secondary, Higher secondary, Graduate and above), Occupation (unpaid, student, self-employed, casual 
labour, pension, salaried, other) and Monthly per capita Consumption Expenditure (MPCE) quintile.

\section{Methodology}

We calculated the total maternity care expenditure by adding all the components of maternity care (ANC, Delivery expenditure, and PNC) and divided it with household size to estimate per capita expenditure.

Total Maternity Care Expenditure $(\mathrm{TMCE})=\mathrm{ANCE}+$ Delivery Expenditure+ PNCEH/ Household Size

$$
\mathrm{TMCE}=\frac{A N C E+D C E+P N C E 1}{\text { HHSize }}
$$

where,

TMCE $=$ Total Maternity Care Expenditure.

$\mathrm{ANCE}=$ Antenatal Care Expenditure.

$\mathrm{DCE}=$ Delivery Care Expenditure.

PNCE $=$ Postnatal Care Expenditure.

HH Size $=$ Household Size.

We calculated mean expenditure for maternity care expenditure and percentages for the the people experiencing catastrophic expenditure.. Inorder to make these costs comparable across timelines we have controlled for inflation using the consumer price index.

The multinomial binary logistic regression was used to analyse the impact of socio-economic variables on distress financing in the study. As with binary logistic regression, even multinomial logistic regression sets aside one category as a base category. Hence there are always $\mathrm{C}-1$ parameters. Then, the logit of each non-reference category $j=1, C-12$ against the reference category 0 depends on the values of the explanatory variables through:

$$
\log \left(\frac{\pi \mathrm{i}(\mathrm{j})}{\pi \mathrm{i}(0)}\right)=\alpha(\mathrm{j})+\beta 1(\mathrm{j}) \mathrm{X} 1 \mathrm{i}+\cdots+\beta \mathrm{k}(\mathrm{j}) \mathrm{Xki}
$$

For each $j=1, C-1$ where $(j)$ and $\beta 1(j), \ldots, \beta k(j)$ are unknown population parameters, $\pi i(0)$ and $\pi i(1)$ are probability parameters and $\mathrm{k}$ is the number of explanatory variables.

We used Stata 15.0 software for the analysis as well as the Geoda 1.16 software to make a spatial analysis of the state-level maps.

\section{Results}

Trends of total maternity care expenditure, delivery care expenditure and different components of average delivery care expenditure (in Rs.), India, 2014-15 to 2017-18

Figure 1 shows the average total maternity care and delivery care expenditures were Rs. 6076 and Rs. 5276 respectively in 2017-18. However, delivery care expenditure consisted lion's share (almost $90 \%$ ) of maternity care expenditure in India. Figures $2 \mathrm{a}$ and $\mathrm{b}$ shows the average total maternity care expenditure by Indian states from 2014-15 to 2017-18. The average expenditure remained high among the developed states like Andhra Pradesh, Telangana, Tamil Nadu, Goa, Gujarat and Punjab in the both time periods. But in the states like Madhya Pradesh, Uttarakhand, Manipur the expenditure has increased form the period 2014-15 to 2017-18.

It is also found that the majority of delivery care expenditures were comprising of package components, doctor's/ surgeon's fee, and spending on medicines (Table 1). Further, there was not much difference in componentwise average delivery care expenditure from 2014-15 to 2017-18, except for the package component in India.

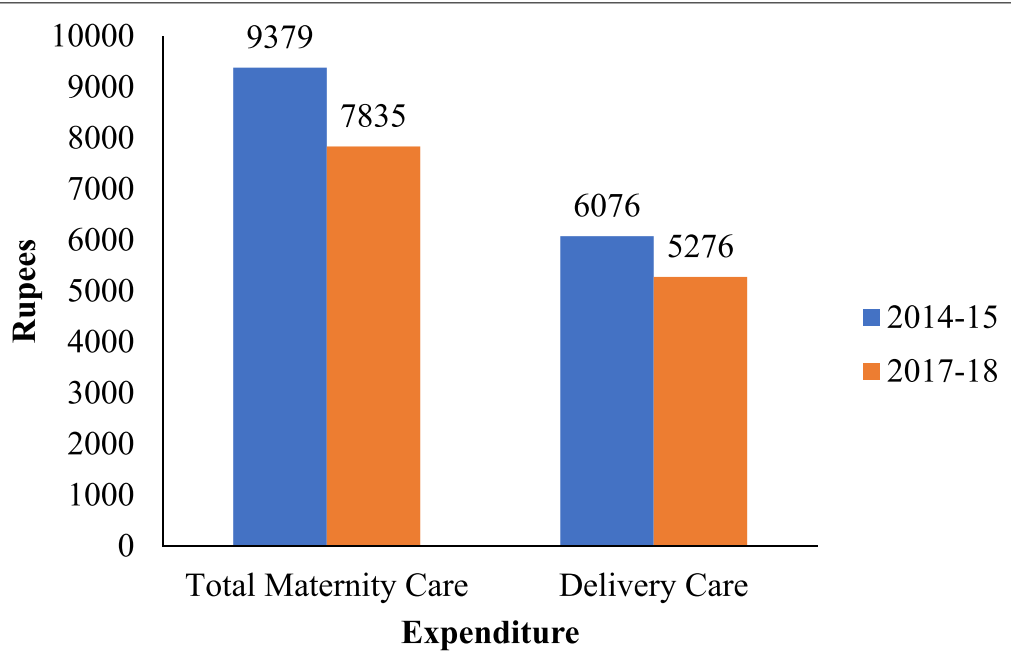

Fig. 1 Trends of total maternity care expanditure and delivery care expenditure, India, 2014-17 


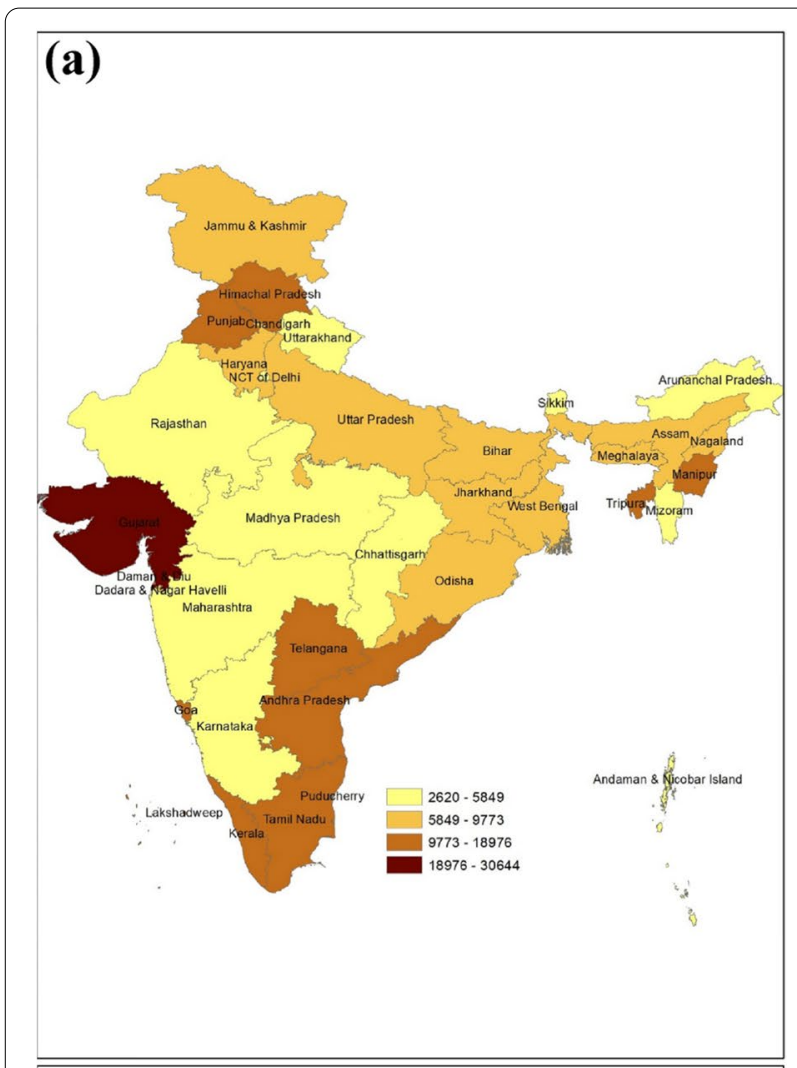

(b)

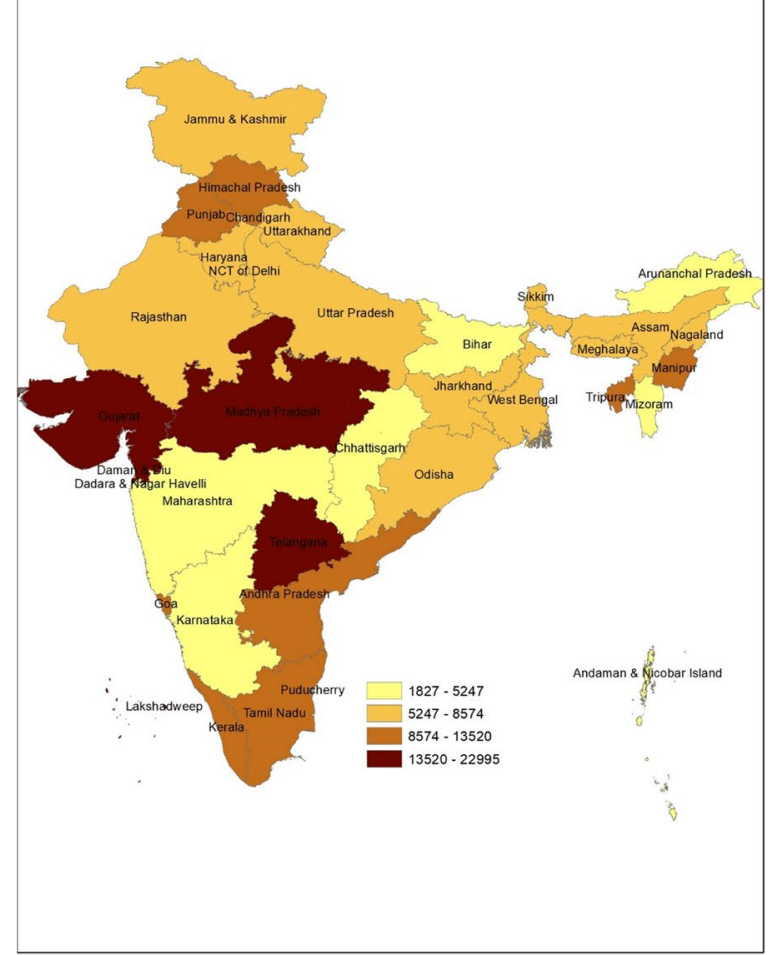

Fig. 2 a State wise total maternity care expenditure, 2014-15, India. b State wise total maternity care expenditure, 2017-18, India
Trends of distress financing for maternity care expenditure Table 2 depicts the percentage of households using distress financing with different selected socio-economic characteristics during 2014-15 to 2017-18. Results show that in India, distress financing decreased from $17 \%$ in $2014-15$ to $12 \%$ in $2017-18$. However, the percentage of households using distress financing in the $45+$ age group increased from $7 \%$ in $2014-15$ to $28 \%$ in $2017-18$. Among wealth quartile, the percentage was low among $4^{\text {th }}$ quartile $(9 \%)$. The percentage of SC households (14.1\%) experiencing distress financing was comparatively high compared to other categories in 2017-18.

The study also finds that $11 \%$ of the population belonging to EAG + A states incurred distress financing in 2017-18. Among the EAG + A states, the percentage of households facing distress financing was highest in Bihar (25.1\%) in 2014-15 and it decreased to 7.7\% in 2017-18. Only in Madhya Pradesh, the percentage of families facing distress financing increased $(8.9 \%$ in $2014-15$ to $18.3 \%$ in 2017-18), and Madhya Pradesh had the highest rate of households experiencing distress financing in 2017-18. Along with Madhya Pradesh, the households from Uttar Pradesh, Madhya Pradesh, Jharkhand, Tamil Nadu, Andhra Pradesh, Telangana, and Karnataka were also experiencing higher distress financing (Fig. 3).

\section{Coping mechanism for the total maternity care expenditure}

Table 3 depicts the incidence of using various sources of finance as a coping mechanism by households to meet the total maternity care expenditure in India during 2017-18. More than half of the households (58\%) utilized savings as a coping mechanism to meet maternity care expenditure in India. In contrast, about one-third of households used insurance for the same. Financial support from friends and relatives, and the sale of assets, contribute towards almost $8 \%$ of the total maternity care expenditure.

We found that more than $64 \%$ of households from rural areas used savings to meet the maternity care expenditure, while $55 \%$ of the urban population did so. However, more urban households (37\%) utilized insurance than rural households (26\%). As far as the caste of the respondents was concerned, the highest percentage of SC households utilized household savings than other caste people. Nevertheless, the percentage of households using insurance was higher among the non-SC/ST category. Among the wealth quartiles, 40 percent of households who were in $4^{\text {th }}$ quartile utilized insurance, and 53 percentage of households used borrowings, whereas 66 percent of households in quartile 1 used household savings, and 22 percentage households used insurance as the coping mechanism to meet maternity care expenditure. 
Table 1 Components of Average Delivery Care Expenditure (in INR.), India, 2014-15 to 2017-18

\begin{tabular}{|c|c|c|c|c|c|c|}
\hline \multirow[t]{2}{*}{ Variables } & \multicolumn{2}{|l|}{$\mathrm{EAG}+\mathrm{A}$} & \multicolumn{2}{|l|}{ Non-EAG } & \multicolumn{2}{|l|}{ India } \\
\hline & 2014-15 & 2017-18 & 2014-15 & 2017-18 & 2014-15 & 2017-18 \\
\hline Package Component & - & 1291 & 38,353 & 3622 & 38,353 & 2366 \\
\hline Doctor's/ Surgeon's fee & 812 & 895 & 2498 & 2476 & 1669 & 1624 \\
\hline Expenditure on Medicines & 1286 & 1414 & 387 & 2187 & 1733 & 1770 \\
\hline Expenditure on Diagnostic Tests & 426 & 502 & 60 & 1081 & 662 & 769 \\
\hline Expenditure on Bed Charges & 389 & 423 & 418 & 1049 & 720 & 712 \\
\hline Other medical expenditures & 332 & 361 & 628 & 880 & 533 & 601 \\
\hline Expenditure on Transport & 465 & 451 & 1014 & 584 & 494 & 512 \\
\hline Other Non-medical Expenditure & 717 & 725 & 1238 & 1162 & 878 & 926 \\
\hline Total & 4180 & 3491 & 8009 & 7362 & 6076 & 5276 \\
\hline
\end{tabular}

Note: There is no samples for package component in EAG states for the period 2014-15

Fifty-four percent salaried mothers used insurance, and $39 \%$ of households were more dependent on family savings. Eighty percent of households used household savings as a coping strategy in which the women were literate without schooling. The percentage of households having insurance increased with education. Across religious groups, households from Muslim and Hindu communities almost equally (62\%) used household income or savings as a coping mechanism in maternity care.

Among EAG + A states, 67.9 percent households were dependent upon household savings and it was 63.6 percentage in non-EAG states. The proportion of households that met their expenditure through borrowings was almost the same in both EAG + A and non-EAG states (3.4\% and 3.5\% respectively). Nevertheless, the scenario reversed itself in the case of insurance. The proportion of mothers who used insurance in EAG + A states (22\%) was less than non- EAG states (37\%). Among the EAG + A states, a low percentage of households had savings in Jharkhand (49.5\%) and Rajasthan (40.2\%) to bear the maternity care expenditure. In the case of insurances, it was low in Madhya Pradesh and highest in Rajasthan (54.6\%).

\section{Determinants of using distress financing as a coping mechanism for maternity care expenditure}

Table 4 Multinomial Logistic Regression shows the determinants of the type of coping mechanisms among households. Relative risk is the probability of an event occurring in the exposed group versus the probability of the event occurring in the non-exposed group. It gives the relative risk ratio of use of different sources of finance with reference to Savings.

The households with a high burden of maternity care expenditure were at significantly higher risk (RR: 2.59; $P<0.01$; 95\% CI: 2.15-3.13) of using borrowings as compared to Income/Savings to meet the maternity care expenditure. The mothers using private health facilities were more likely to use borrowings (RR: $3.07 ; P<0.01$; 95\% CI: 2.56-3.68) than the mothers using public health facilities. Urban households were at lower risk of using borrowings (0.72; $P<0.01 ; 95 \%$ CI: 0.62-0.85) compared to income/savings with rural households. Urban households were at a higher chance of using insurance (RR: $1.11 ; P<0.01 ; 95 \% \mathrm{CI}: 1.05-1.18)$ as compared to income/ savings than their rural counterparts. The mothers belonging to the $\mathrm{SC}$ caste were at significantly higher risk (RR: $1.43 ; P<0.1$; 95\% CI: $1.07-1.91$ ) of using borrowings compared to the use of income/savings than their counterparts. There was a low risk of dependent upon borrowings compared to income and savings when the mothers were educated secondary and above. The educated mothers were more likely to use insurance (Primary $=1.21$; $P<0.01$; 95\% CI: 1.09-1.34; Secondary $=1.29 ; P<0.01$; 95\% CI: 1.17-1.41; Higher secondary $=1.35 ; P<0.01 ; 95 \%$ CI: $1.21-1.5$; Graduate and above $=1.81 ; P<0.01 ; 95 \%$ CI: $1.62-2.02)$ than the women who had no education or who were in the literate without schooling group as compared to income and savings. The households with a high burden of maternity care expenditure were at significantly higher risk (RRR: 1.39; $P<0.01 ; 95 \%$ CI:1.28-1.52) of using insurance as compared to the use of Income/Savings to meet the maternity care expenditure. The mothers belonged to $2^{\text {nd }}, 3^{\text {rd }}$ and $4^{\text {th }}$ quartiles were more likely to use insurance (quartile $2=1.1 ; P<0.1 ; 95 \% \mathrm{CI}: 1.01-1.2$; quartile $3=1.31 ; P<0.01 ; 95 \% \mathrm{CI}: 1.2-1.42$; quartile $4=1.74 ; P<0.01 ; 95 \%$ CI: $1.59-1.9)$ than the $1^{\text {st }}$ quartile mothers as compared to income and savings.

The households with a high burden of maternity care expenditure were at significantly higher risk (RRR: 1.27; $P<0.1$; 95\% CI:1.02-1.57) of using other coping mechanisms as compared to the use of Income/Savings. The 
Table 2 Percentage of households using distress financing by selected socio-economic variables and EAG + A and non-EAG states, India,2014-15 to 2017-18

\begin{tabular}{|c|c|c|c|}
\hline Variables & Categories & $2014-15$ & 2017-18 \\
\hline \multirow[t]{4}{*}{ Age of the mother (in Years) } & $15-24$ & 19.5 & 14.3 \\
\hline & $25-34$ & 15.0 & 11.4 \\
\hline & $35-44$ & 13.3 & 8.8 \\
\hline & $45+$ & 6.6 & 28.0 \\
\hline \multirow[t]{2}{*}{ Residence } & Rural & 17.7 & 12.7 \\
\hline & Urban & 15.2 & 11.7 \\
\hline \multirow[t]{6}{*}{ Literacy of mother } & No literate & 19.4 & 13.7 \\
\hline & Literate without schooling & 23.9 & 6.9 \\
\hline & Primary & 16.8 & 11.7 \\
\hline & Secondary & 17.7 & 13.2 \\
\hline & Higher secondary & 16.4 & 12.3 \\
\hline & Graduate and above & 10.6 & 10.3 \\
\hline \multirow[t]{7}{*}{ Occupation of the mother } & Unpaid & - & 12.4 \\
\hline & Student & - & 8.6 \\
\hline & Self-employed & - & 14.6 \\
\hline & Casual labour & - & 18.2 \\
\hline & Pension & - & 8.5 \\
\hline & Other & - & 18.7 \\
\hline & Salaried & - & 9.3 \\
\hline \multirow[t]{3}{*}{ Caste } & ST & 12.3 & 10.9 \\
\hline & SC & 19.1 & 14.1 \\
\hline & Others & 17.1 & 12.1 \\
\hline \multirow[t]{3}{*}{ Religion } & Hindu & 17.1 & 12.8 \\
\hline & Muslim & 18.0 & 11.6 \\
\hline & Others & 12.3 & 9.6 \\
\hline \multirow[t]{4}{*}{ Wealth quartile } & Quartile 1 & 18.4 & 13.2 \\
\hline & Quartile 2 & 19.3 & 13.8 \\
\hline & Quartile 3 & 17.1 & 13.2 \\
\hline & Quartile 4 & 13.4 & 9.5 \\
\hline \multirow[t]{2}{*}{ Type of health facility } & Public & 13.3 & 11.2 \\
\hline & Private & 23.6 & 15.4 \\
\hline \multirow[t]{10}{*}{$E A G+A$} & Uttarakhand & 0.7 & 8.1 \\
\hline & Rajasthan & 7.8 & 7.5 \\
\hline & Uttar Pradesh & 14.2 & 14.3 \\
\hline & Bihar & 25.1 & 7.7 \\
\hline & Assam & 3.3 & 3.6 \\
\hline & Jharkhand & 13.4 & 15.0 \\
\hline & Odisha & 22.4 & 6.5 \\
\hline & Chhattisgarh & 13.7 & 6.8 \\
\hline & Madhya Pradesh & 8.9 & 18.3 \\
\hline & $E A G+A$ & 14.0 & 11.3 \\
\hline Non-EAG & Non-EAG & 20.0 & 13.8 \\
\hline Total & India & 17.0 & 12.5 \\
\hline
\end{tabular}




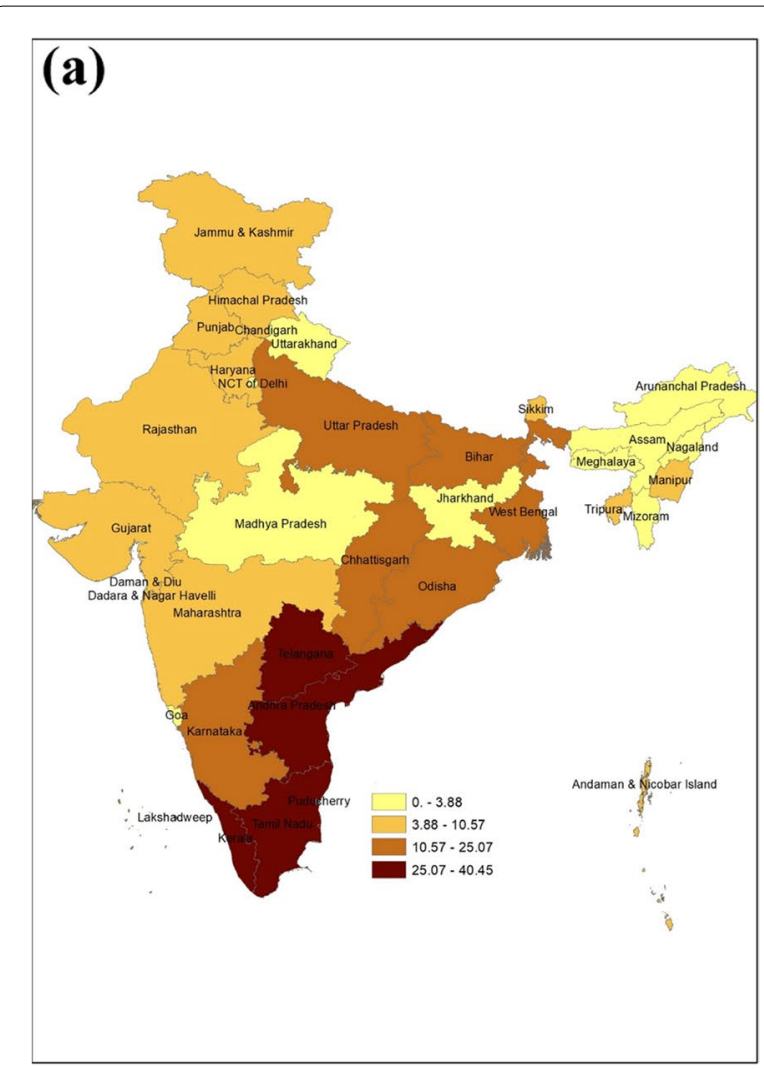

(b)

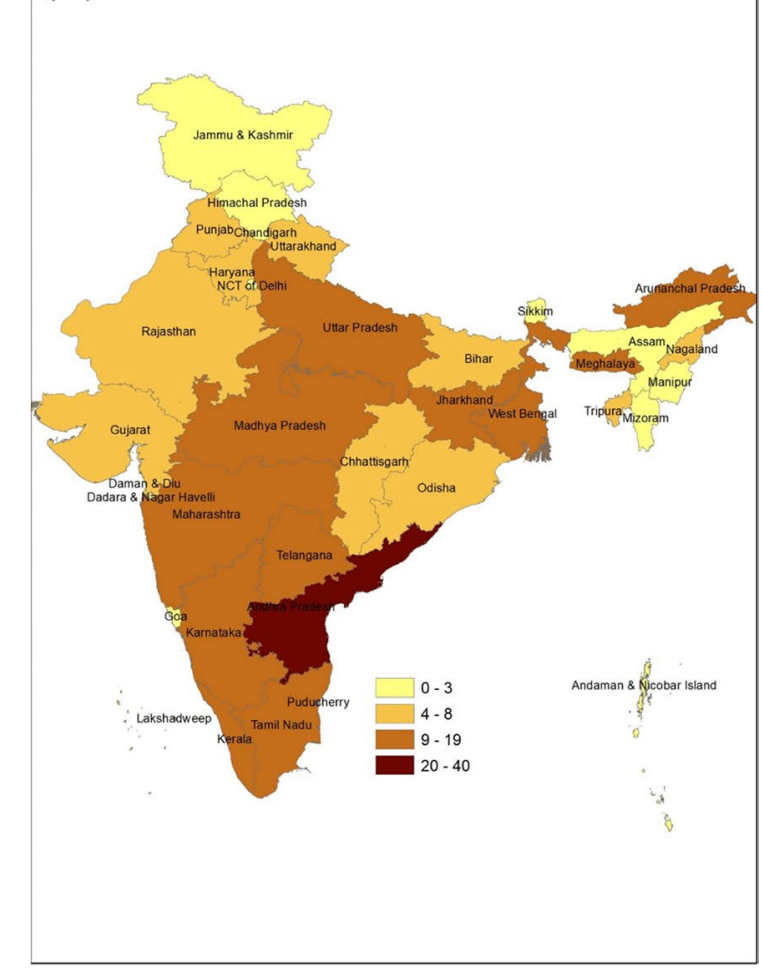

Fig. 3 a Percentage of People Experiencing Distress Financing for Maternity Care Expenditure, 2014-15, India. b Percentage of People Experiencing Distress Financing for Maternity Care Expenditure, India, 2017-18

households belonged to Quantile 4 (rich) category were at significantly lower risk (RRR: $0.63 ; P<0.01 ; 0.95 \%$ CI:0.510.77 ) of using other coping mechanisms as compared to the use of Income/Savings to cope with the households belonged to other three categories. The maternal who took treatment in a private health facility were at significantly lower risk (RRR: $0.82 ; P<0.1 ; 95 \%$ CI:0.7- 0.98) of using other coping mechanisms as compared to the use of Income/Savings to cope with the maternal who took treatment in the public health facility.

Figure 4 shows the concentration curves (CCs) of the cumulative proportion of households ranked by MPCE on the $\mathrm{x}$-axis upon the cumulative proportions of households using the different coping mechanisms for maternity care expenditure. The concentration curves for savings, borrowings, and other sources show the level of inequality among different quantile. A higher concentration of savings is observed among the wealthier group, whereas poorer households are experiencing a higher concentration of borrowing and other sources. On the other hand, the incidence of distress financing follows a socio-economic gradient where economically weaker sections have a higher risk of financial hardship in maternity care. The comparison between the slope of the CC during 2014-15 to 2017-18 shows the incidence of other sources continues to the pro-rich. At the same time, the slope of the CC for borrowings has moved closer toward the line of equality, demonstrating that the incidence is less concentrated among economically weaker sections in 2017-18 than in 2014-15.

\section{Discussion}

Over the last few decades, the world has witnessed a significant improvement in health in general and maternal health in particular [31]. The rise in health expenditure coincided with this improvement [32]. It is usually presumed that increase in health expenditure will automatically improve the health outcome. Countries like India still struggle to prevent maternal mortality and improve maternal health at a promising level [33, 34]. In particular, the EAG states are experiencing a massive burden of health care expenditure, particularly the maternity care expenditure [31]. Increasing the utilization of Maternity care is one of the aims of the National Health Mission (NHM) and others to reduce maternal mortality, neonatal mortality and decrease catastrophic spending on 
Table 3 Incidence (\%) of Use of Different Sources of Finance as a Coping Mechanism to meet the Total Maternity care by Households in India, 2017-18

\begin{tabular}{|c|c|c|c|c|c|}
\hline Variables & Categories & $\begin{array}{l}\text { Savings/House Hold } \\
\text { Income }\end{array}$ & Borrowings & Insurance & Others \\
\hline \multirow[t]{4}{*}{ Age of the Mother (in Years) } & $15-24$ & 61.4 & 3.8 & 27.3 & 6.8 \\
\hline & $25-34$ & 61.1 & 3.1 & 30.6 & 4.8 \\
\hline & $35-44$ & 62.5 & 3.2 & 30.3 & 3.4 \\
\hline & $45+$ & 46.8 & 2.1 & 30.4 & 20.7 \\
\hline \multirow[t]{2}{*}{ Residence } & Rural & 63.6 & 3.7 & 26.4 & 5.9 \\
\hline & Urban & 54.6 & 2.7 & 37.4 & 4.8 \\
\hline \multirow[t]{6}{*}{ Literacy of mother } & No literate & 64.7 & 3.6 & 23.9 & 7.5 \\
\hline & Literate without schooling & 80.0 & 2.1 & 15.6 & 2.3 \\
\hline & Primary & 63.8 & 3.0 & 26.8 & 5.5 \\
\hline & Secondary & 61.8 & 3.8 & 28.0 & 5.9 \\
\hline & Higher secondary & 59.9 & 3.4 & 31.6 & 5.0 \\
\hline & Graduate and above & 51.5 & 2.8 & 42.2 & 3.2 \\
\hline \multirow[t]{7}{*}{ Occupation of the mother } & Unpaid & 61.6 & 3.4 & 29.1 & 5.5 \\
\hline & Student & 65.3 & 0.1 & 27.1 & 7.6 \\
\hline & Self employed & 61.0 & 4.1 & 26.2 & 8.8 \\
\hline & Casual labour & 61.7 & 3.8 & 22.6 & 10.6 \\
\hline & Pension & 75.7 & 0.0 & 16.9 & 7.4 \\
\hline & Other & 52.1 & 10.3 & 34.2 & 3.0 \\
\hline & Salaried & 39.9 & 3.2 & 54.3 & 2.4 \\
\hline \multirow[t]{3}{*}{ Caste } & ST & 59.0 & 2.2 & 33.5 & 5.0 \\
\hline & SC & 63.2 & 4.3 & 25.7 & 6.4 \\
\hline & Others & 61.0 & 3.3 & 29.8 & 5.4 \\
\hline \multirow[t]{3}{*}{ Religion } & Hindu & 61.5 & 3.6 & 28.8 & 5.7 \\
\hline & Muslim & 62.1 & 3.0 & 28.4 & 5.9 \\
\hline & Others & 54.0 & 2.2 & 40.8 & 3.0 \\
\hline \multirow[t]{4}{*}{ Wealth Quartile } & Quartile 1 & 66.6 & 3.8 & 22.4 & 6.9 \\
\hline & Quartile 2 & 64.3 & 3.9 & 24.7 & 6.7 \\
\hline & Quartile 3 & 60.2 & 3.8 & 29.8 & 5.6 \\
\hline & Quartile 4 & 53.8 & 2.2 & 40.4 & 3.1 \\
\hline \multirow[t]{2}{*}{ Type of Health Facility } & Public & 64.85 & 2.0 & 26.56 & 6.5 \\
\hline & Private & 53.95 & 6.8 & 35.82 & 3.4 \\
\hline \multirow[t]{10}{*}{$E A G+A$} & Uttarakhand & 72.1 & 2.9 & 20.2 & 4.9 \\
\hline & Rajasthan & 40.2 & 3.5 & 54.6 & 0.8 \\
\hline & Uttar Pradesh & 74.8 & 3.8 & 12.1 & 8.7 \\
\hline & Bihar & 74.4 & 4.5 & 19.1 & 2.1 \\
\hline & Assam & 76.3 & 2.4 & 20.6 & 0.8 \\
\hline & Jharkhand & 49.5 & 2.7 & 41.8 & 5.5 \\
\hline & Odisha & 64.4 & 2.3 & 31.4 & 2.0 \\
\hline & Chhattisgarh & 79.9 & 2.0 & 14.3 & 3.3 \\
\hline & Madhya Pradesh & 72.5 & 2.4 & 9.8 & 14.6 \\
\hline & $\mathrm{EAG}+\mathrm{A}$ & 67.9 & 3.4 & 22.3 & 5.9 \\
\hline \multirow[t]{2}{*}{ Non-EAG } & Non-EAG & 53.6 & 3.5 & 37.3 & 5.3 \\
\hline & India & 57.8 & 3.1 & 34.4 & 4.4 \\
\hline
\end{tabular}


maternal care [18]. This study provides the situational analysis for maternity care expenditure and throws light on how the population meets their distress financing in post NHM periods (2014-15 \& 2017-18).

Results from this study depicted that, the catastrophic maternity care expenditure has decreased from the period $2014-15$ to $2017-18$ [18, 30]. In this study, we found that doctor's and medical fees are the main components in the expenditure, which plays an important role in increasing the expenditure and the households fall into a catastrophic trap [30]. of the reason might be poor health expenditure and fewer doctors in the country [35]. India has a much lower proportion doctor population ratio than the WHO norm [36].

The percentage of households using distress financing is higher among the poorest section. But, still, there is a high percentage of households using distress financing among wealthy people. This may be because of the high aspiration of people to hospitals that have better health facilities [25, 27]. It is also documented in several previous research that the health transition is much faster than the socio-economic transition in the country [3,37], and that leads to usage of distress financing even among rich households.
The study also highlighted that people from the SC caste are experiencing high distress financing. Similar finding observed in other previous studies $[38,39]$ depict that because of lack of health knowledge, low education, and low economic status among the SC communities [40-42]. Similarly, when we analysed the regional variation, EAG + A states, particularly Madhya Pradesh, is experiencing a high level of distress financing [8]. We also found that in developed states like Andhra Pradesh and Telangana a high percentage of households experiencing distress financing. This may be because of the aspiration of better health care access, leading to high health care expenditure $[12,23]$. The out-of-pocket expenditure on delivery care in developing countries like African countries Kenya, Tanzania is much lower. Still, it is higher in developed countries like United States, Poland, Israel, Switzerland, and Russia. This is because they provide highly subsidized maternity health care facilities in comparison with India [43, 44]. The percentage of households going for treatment in private hospitals are using higher levels of borrowings than the public hospital utilizing patients $[25,27]$. The expenditure in public hospitals is lower than the private hospitals. But, due to the poor health infrastructure in public hospitals, people prefer

Table 4 Multinomial Logistic Regression showing Association between Coping Mechanism and Selected Socio-economic Variables

\begin{tabular}{|c|c|c|c|c|c|c|c|}
\hline \multirow[t]{2}{*}{ Coping Mechanisms } & \multirow[b]{2}{*}{ Variables } & \multicolumn{2}{|c|}{ Borrowings } & \multicolumn{2}{|c|}{ Insurance } & \multicolumn{2}{|c|}{ Other Coping Mechanisms } \\
\hline & & RRR & $95 \%$ Conf. Interval & RRR & $95 \%$ Conf. Interval & RRR & $95 \%$ Conf. Interval \\
\hline \multirow[t]{2}{*}{ CMCE } & CMCE (no) ${ }^{\circledR}$ & & & & & & \\
\hline & CMCE (yes) & $2.59^{* * *}$ & $(2.15,3.13)$ & $1.39^{* * *}$ & $(1.28,1.52)$ & $1.27^{*}$ & $(1.02,1.57)$ \\
\hline \multirow[t]{2}{*}{ Residence } & Rural $^{\circledR}$ & & & & & & \\
\hline & Urban & $0.72^{* * *}$ & $(0.62,0.85)$ & $1.11^{* * *}$ & $(1.05,1.18)$ & 0.99 & $(0.87,1.14)$ \\
\hline \multirow[t]{6}{*}{ Literacy of mother } & No literate ${ }^{\circledR}$ & & & & & & \\
\hline & Literate without schooling & 0.44 & $(0.16,1.22)$ & 0.73 & $(0.51,1.04)$ & 0.64 & $(0.32,1.27)$ \\
\hline & Primary & 0.83 & $(0.66,1.06)$ & $1.21^{* * *}$ & $(1.09,1.34)$ & 0.83 & $(0.68,1.02)$ \\
\hline & Secondary & $0.65^{* * *}$ & $(0.53,0.81)$ & $1.29^{* * *}$ & $(1.17,1.41)$ & 0.95 & $(0.79,1.13)$ \\
\hline & Higher secondary & $0.53^{* * *}$ & $(0.41,0.69)$ & $1.35^{* * *}$ & $(1.21,1.5)$ & $0.78^{*}$ & $(0.62,0.98)$ \\
\hline & Graduate and above & $0.38^{* * *}$ & $(0.29,0.51)$ & $1.81^{* * *}$ & $(1.62,2.02)$ & $0.75^{*}$ & $(0.58,0.97)$ \\
\hline \multirow[t]{4}{*}{ Wealth quartile } & Quartile ${ }^{\circledR}$ & & & & & & \\
\hline & Quartile 2 & 1.22 & $(0.98,1.5)$ & $1.1^{*}$ & $(1.01,1.2)$ & 1 & $(0.85,1.18)$ \\
\hline & Quartile 3 & $1.24^{*}$ & $(1.01,1.53)$ & $1.31^{* * *}$ & $(1.2,1.42)$ & 0.86 & $(0.73,1.02)$ \\
\hline & Quartile 4 & 1.07 & $(0.84,1.37)$ & $1.74^{* * *}$ & $(1.59,1.9)$ & $0.63^{* * *}$ & $(0.51,0.77)$ \\
\hline \multirow[t]{3}{*}{ Caste of the mother } & $\mathrm{ST} T^{\circledR}$ & & & & & & \\
\hline & SC & $1.43^{*}$ & $(1.07,1.91)$ & $0.51^{* * *}$ & $(0.46,0.56)$ & 1.23 & $(0.99,1.53)$ \\
\hline & Others & 1.12 & $(0.86,1.46)$ & $0.51^{* * *}$ & $(0.48,0.56)$ & 1.19 & $(0.98,1.45)$ \\
\hline \multirow[t]{3}{*}{ Type of health facility } & Govt/Public Hospital ${ }^{\circledR}$ & & & & & & \\
\hline & Private Hospitals & $3.07^{* * *}$ & $(2.56,3.68)$ & 1.05 & $(0.98,1.13)$ & $0.82^{*}$ & $(0.7,0.98)$ \\
\hline & Constant & $0.04^{* * *}$ & $(0.03,0.05)$ & $0.54^{* * *}$ & $(0.48,0.6)$ & $0.09 * * *$ & $(0.07,0.11)$ \\
\hline
\end{tabular}

Note: The number of samples for the sale of physical assets category are very less for regression analysis. ${ }^{\circledR}=$ Reference category, $P<0.1={ }^{*}, P<0.04={ }^{* *}, P<0.01={ }^{* * *}$ Level of significance for multinomial logistic regression 
Panel A

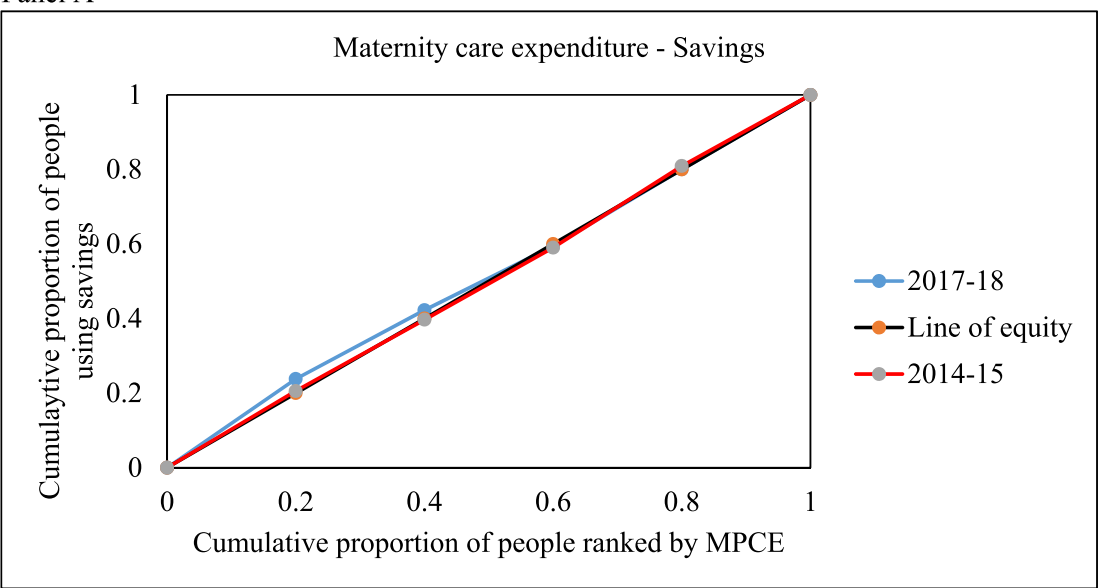

Panel B

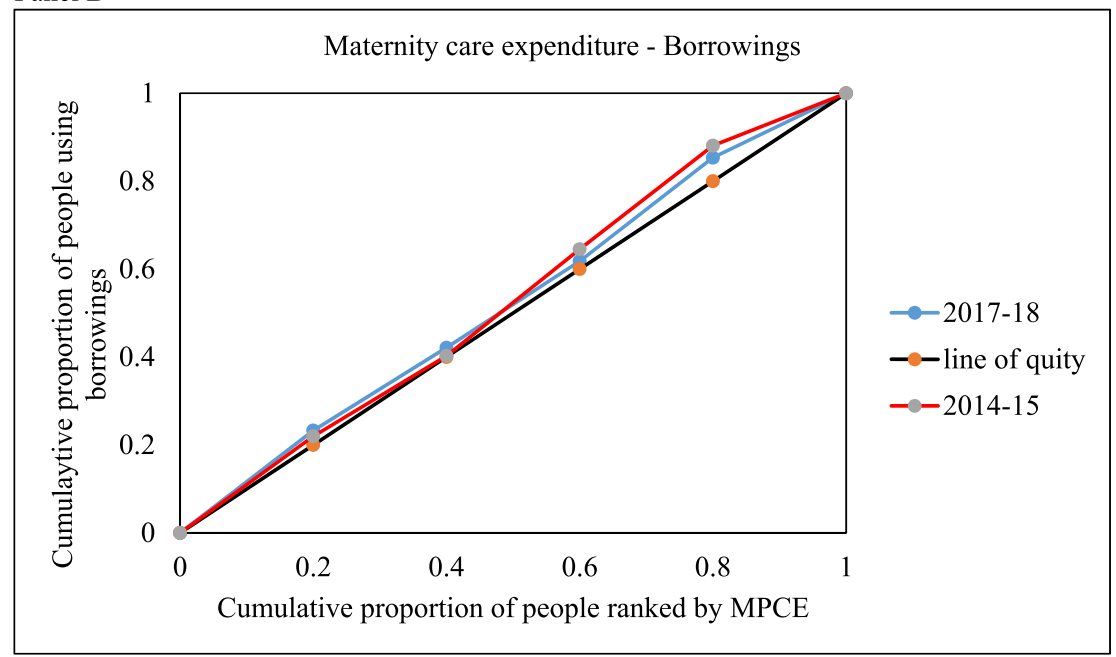

Panel C

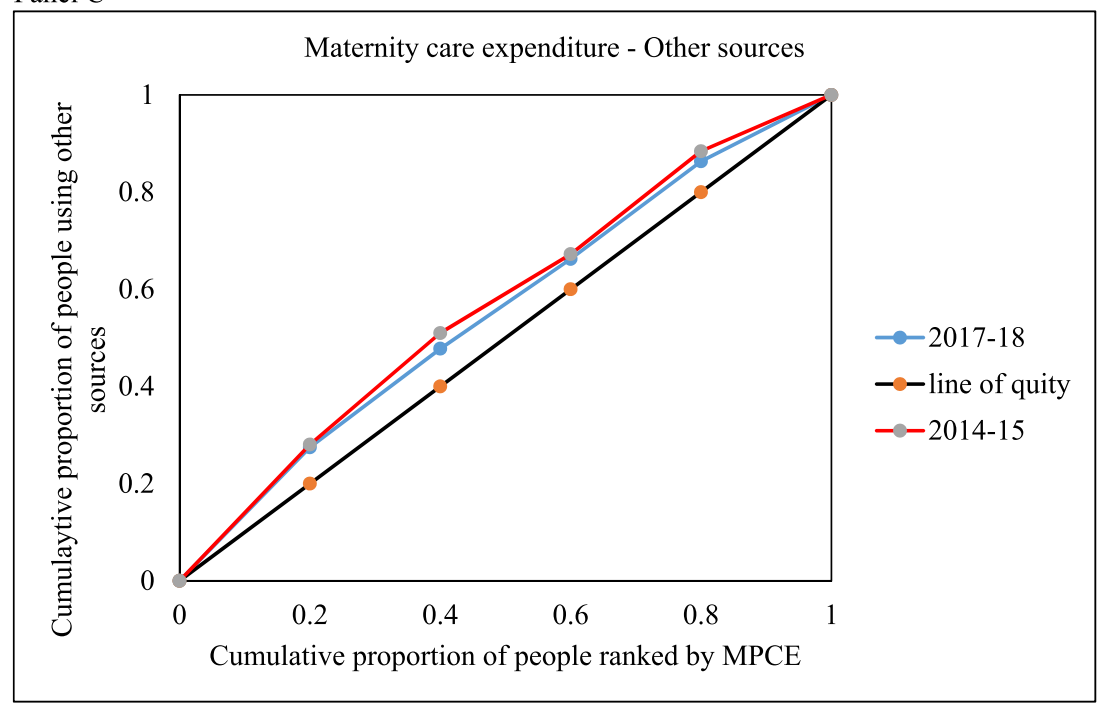

Fig. 4 Concentration curves for savings, borrowings and other sources 
private hospitals even though they will fall in the catastrophic expenditure trap [35].

This study also shows how people are using different sources of finance as coping mechanisms to meet maternity care expenditure. The study found that around sixty percent of households are using household savings to meet the maternity expenditure. Similar finding is also observed in the previous studies [30,39]. The percentage of households using insurance in rural areas is less than the urban households. The lack of awareness about the benefit of insurance coverage is responsible for the same $[45,46]$. The literate households are using savings as a coping strategy than their counterpart. Studies have documented that the knowledge to save and awareness about schemes is much higher among literate households than the less educated households [17, 30]. We also found that borrowings are the primary source used to cope with distress financing in all states $[8,25]$. Urban households are at a lower risk of using borrowing as a coping mechanism than rural households. Previous studies also documented that rural households have a massive burden for borrowing money to cope with health care expenses [27, 47]. Rural households have low health insurance, and struggling to arrange daily expenses are significant factors [9].

The maternal using private health facilities were more likely to use borrowings than the mothers using public health facilities because the cost of treatment is high comparing to public hospitals [39]. Urban maternals were at lower risk of using borrowings compared to income/ savings with rural households. The women belonging to the SC caste were at significantly higher risk of using borrowings compared to the use of income/savings than their counterparts because of lack of health knowledge, low education and low economic status among the SC communities [40-42]. There was a low risk of dependent upon borrowings compared to income and savings when the mothers were educated secondary and above. As expected the educated mothers were more likely to use insurance than the women who had no education or who were in the literate without schooling group as compared to income and savings.

The Government of India announced the Pradhan Mantri Matru Vandana Yojana (PMMVY) in January 2017, which provided partial compensation or wage loss in the form of cash support of INR 5000 to pregnant and nursing women. A sum of INR 1000 is given upon early pregnancy registration at an Anganwadi Centre (AWC) / Approved Health Facility, a sum of INR 2000 after 6 months of pregnancy on receiving at least one ante-natal check-up (ANC), and a sum of INR 2000 after child birth is registered and the child has received the first cycle of Bacillus Calmette Guerin (BCG), Oral
Polio Vaccine (OPV) and Diphtheria vaccines. The programme aims to improve pregnant women's and breastfeeding mothers' health-seeking behaviour. However the high codt of maternity care imperiments the success of this programme, our findings show a slight reduction in maternity care expenditure and distress financing indicating the positive impact of PMMVY [48]. Despite the reduction, the current mean expediture for maternity care and its related distress financing are high. It is higher among SC, poor, less educated maternals and rural households. Better improvement of PMMVY among these vulnerable groups will instrument further reduction in materternity cost. For the same we also suggest further enquiries into pitfalls of PMMVY implementation process.

\section{Conclusions}

A high level of out-of-pocket expenditure (OOPE) is indicative of a regressive health care system. There have been several policies and programs that aim at the betterment of maternity care service utilisation, wherein the ultimate aim of all the programs like JSY is to decrease maternal mortality rate by providing health services in the needed times remarkably increasing the institutional delivery for which the policies and programs offer cash incentives and thereby increasing the utilisation and to reduce burden among the household. The study found that even though many programs for maternity care services are there, the maternity care expenditure, particularly the delivery care expenses, is very high in many states. Obviously India should increase subsidized maternity care facilities to decrease catastrophic maternity expenditure among households. The study also highlighted that the population prefers private hospitals for delivery care instead of higher expenses at private hospitals. Therefore, it can be suggested that improving public health facilities for maternity care are required to reduce the catastrophic maternity care expenditure on households that may finally reduce the economic burden. Cost of delivery plays a central role in increasing the total maternity care expenditure. So, better health facilities are needed in local healthcare centers, leading to the low cost delivery. The doctor's fee is the main component in delivery care expenditure. The proportion of doctor's fees is high in comparing with other components. The doctor's fee is nominal in public health facilities, but the fee is high in private sectors. So, implementation of policy to maintain the doctor's fee standard in all health facilities should be regulated. Insurance coverage for maternity care expenditure is highly recommended for all the women in the reproductive age group to lower catastrophic maternity care expenditure and out-of-pocket expenditure in the country. 


\section{Limitations}

This study has some limitations. First, the expenditure data is self-reported and not verified from other sources. Second, recall bias in reporting the actual expenditure for doctor's fee, medicines expenditure, diagnostic tests expenditure, etc. Third, the study only included direct costs. Finally, in most cases, the expenditures associated with the family members or the persons who accompanied the patients during hospital admission and transportation are not included in the study.

\author{
Abbreviations \\ ANC: Antenatal Care; EAG + A: Empowered Action Group + Assam; MMR: \\ Maternal Mortality Rate; MPCE: Monthly Percapita Consumption Expenditure; \\ NRHM: National Rural Health Mission; NSSO: National Sample Survey Organiza- \\ tion; OBC: Other Backward Class; OOPE: Out-of-pocket Expenditure; PNC: \\ Postnatal Care; SC: Scheduled Caste; ST: Scheduled Tribe; WHO: World Health \\ Organization.
}

\section{Acknowledgements}

The authors are grateful to NSSO for making the data available for this study.

\section{Authors' contributions}

All authors contributed to the manuscript. SB and MIKS have contributed towards the conception, design, data analysis and interpretation of the data. They drafted and critically revised the manuscript. MA and $\mathrm{BH}$ have contributed toward data analysis, reviewing the manuscript. Moreover, all authors read, revised and approved the final manuscript for submission.

\section{Funding}

We did not receive any grants from any funding agency in public, commercial, or non-profit sectors for conducting this study.

\section{Availability of data and materials}

The study is based on secondary data analysis. No data was collected for this study. The data are available for free on the NSSO website (http://mospi.nic.in/ unit-level-data-report-nss-75th-round-july-2017-june-2018-schedule-250so cial-consumption-health).

\section{Declarations}

\section{Ethics approval and consent to participate}

Since the data are available for free on the NSSO website. There is no need for ethical clearance.

\section{Consent for publication}

Not Applicable.

\section{Competing interests}

We declare that We have no competing interests.

Received: 10 September 2021 Accepted: 21 February 2022 Published online: 03 March 2022

\section{References}

1. World Health Organization. Trends in maternal mortality 2000 to 2017 estimates by WHO, UNICEF, UNFPA, World Bank Group and the United Nations Population Division. 2019.

2. Special bulletin on maternal mortality in India 2016-18 https://censu sindia.gov.in/vital_statistics/SRS_Bulletins/MMR\%20Bulletin\%202016-18. pdf. Accessed on 25 August 2021
3. Schwartz DA. Hypertensive Mothers, Obstetric Hemorrhage, and Infections: Biomedical Aspects of Maternal Death Among Indigenous Women in Mexico and Central America. In Maternal Death and PregnancyRelated Morbidity Among Indigenous Women of Mexico and Central America. Cham: Springer; 2018. pp. 35-50.

4. Serbanescu F, Goldberg HI, Danel I, Wuhib T, Marum L, Obiero W, Conlon CM. Rapid reduction of maternal mortality in Uganda and Zambia through the saving mothers, giving life initiative: results of year 1 evaluation. BMC Pregnancy Childbirth. 2017;17(1):1-14.

5. Nove A, Friberg IK, de Bernis L, McConville F, Moran AC, Najjemba M, Homer CS. Potential impact of midwives in preventing and reducing maternal and neonatal mortality and stillbirths: a Lives Saved Tool modelling study. Lancet Glob Health. 2021;9(1):e24-32.

6. Kyei-Nimakoh M, Carolan-Olah M, McCann TV. Access barriers to obstetric care at health facilities in sub-Saharan Africa-a systematic review. Syst Rev. 2017;6(1):1-16.

7. Pandey A, Ploubidis GB, Clarke L, Dandona L. Trends in catastrophic health expenditure in India: 1993 to 2014. Bull World Health Organ. 2018;96(1):18.

8. Pathak PK, Singh A, Subramanian SV. Economic inequalities in maternal health care: prenatal care and skilled birth attendance in India, 1992-2006. PloS One. 2010;5(10):e13593.

9. Ahmed S, Creanga AA, Gillespie DG, Tsui AO. Economic status, education and empowerment: implications for maternal health service utilization in developing countries. PloS One. 2010;5(6):e11190.

10. Tarekegn SM, Lieberman LS, Giedraitis V. Determinants of maternal health service utilization in Ethiopia: analysis of the 2011 Ethiopian Demographic and Health Survey. BMC Pregnancy Childbirth. 2014;14(1):1-13.

11. Parmar D, Banerjee A. How do supply-and demand-side interventions influence equity in healthcare utilisation? Evidence from maternal healthcare in Senegal. Soc Scie Med. 2019;241:112582.

12. Shahrawat R, Rao KD. Insured yet vulnerable: out-of-pocket payments and India's poor. Health Policy Plan. 2012;27(3):213-21.

13. Aregbeshola BS, Khan SM. Out-of-pocket payments, catastrophic health expenditure and poverty among households in Nigeria 2010. Int J Health Policy Manag. 2018;7(9):798.

14. Basu S, Andrews J, Kishore S, Panjabi R, Stuckler D. Comparative performance of private and public healthcare systems in low-and middleincome countries: a systematic review. PLoS Med. 2012;9(6):e1001244.

15. Skordis-Worrall J, Pace N, Bapat U, Das S, More NS, Joshi W, Osrin D. Maternal and neonatal health expenditure in Mumbai slums (India): a cross sectional study. BMC Public Health. 2011;11(1):1-12.

16. Van Doorslaer E, O'Donnell O, Rannan-Eliya RP, Somanathan A, Adhikari SR, Garg CC, Zhao Y. Catastrophic payments for health care in Asia. Health Econ. 2007;16(11):1159-84.

17. Leone T, James KS, Padmadas SS. The burden of maternal health care expenditure in India: multilevel analysis of national data. Matern Child Health J. 2013;17(9):1622-30.

18. Mohanty SK, Kastor A. Out-of-pocket expenditure and catastrophic health spending on maternal care in public and private health centres in India: a comparative study of pre and post national health mission period. Heal Econ Rev. 2017;7(1):1-15.

19. Griffiths P, Stephenson R. Understanding users'perspectives of barriers to maternal health care use in Maharashtra. INDIA Journal of biosocial science. 2001;33(3):339-59.

20. Husain Z. Health of the national rural health mission. Econ Pol Wkly. 2011:53-60.

21. Garg S, Singh R, Grover M. India's health workforce: current status and the way forward. Natl Med J India. 2012;25(2):111.

22. Khan K, Anwar S, Ahmed M, Kamal MA. Estimation of consumption functions: the case of Bangladesh, India, Nepal, Pakistan and Sri Lanka. Pakistan Business Review. 2015;17(1):113-24.

23. Omgba LD, Djiofack C. Does permanent income hypothesis a solution? An empirical assessment via a dynamic general equilibrium model in developing country. 2019.

24. Arsenault C, Fournier P, Philibert A, Sissoko K, Coulibaly A, Tourigny C, Dumont A. Emergency obstetric care in Mali: catastrophic spending and its impoverishing effects on households. Bull World Health Organ. 2013;91:207-16. 
25. Kumar K, Singh A, James KS, McDougal L, Raj A. Gender bias in hospitalization financing from borrowings, selling of assets, contribution from relatives or friends in India. Soc Sci Med. 2020;260:113222.

26. Sangar S, Dutt V, Thakur R. Economic burden, impoverishment and coping mechanisms associated with out-of-pocket health expenditure: analysis of rural-urban differentials in India. J Public Health. 2018;26(5):485-94.

27. Kastor A, Mohanty SK. Disease-specific out-of-pocket and catastrophic health expenditure on hospitalization in India: do Indian households face distress health financing? PloS One. 2018;13(5):e0196106.

28. Halkett GK, Lobb EA, Rogers MM, Shaw T, Long AP, Wheeler HR, Nowak AK. Predictors of distress and poorer quality of life in High Grade Glioma patients. Patient Educ Couns. 2015;98(4):525-32.

29. Mukherjee S, Singh A, Chandra R. Maternity or catastrophe: a study of household expenditure on maternal health care in India. Health. 2013;5(1):109-18.

30. Goli S, Rammoha A, Pradhan J. High spending on maternity care in India: What are the factors explaining it? PloS One. 2016;1 1(6):e0156437.

31. Vora KS, Mavalankar DV, Ramani KV, Upadhyaya M, Sharma B, lyengar S, lyengar K. Maternal health situation in India: a case study. J Health Popul Nutr. 2009;27(2):184.

32. Rana RH, Alam K, Gow J. Health expenditure, child and maternal mortality nexus: a comparative global analysis. BMC Int Health Hum Rights. 2018;18(1):1-15.

33. Maternal, newborn and child survival https://www.unicef.org/health/ maternal-newborn-and-child-survival. Accessed on 27 August 2019

34. Maternal health https://www.unicef.org/india/what-we-do/maternalhealth. Accessed on 27 August 2019

35. Srinivisan R. "Health Care in India-Vision 2020." New Delhi: Government of India, Planning Commission of India 1;2010.

36. Karan A, Negandhi H, Nair R, Sharma A, Tiwari R, Zodpey S. Size, composition and distribution of human resource for health in India: new estimates using National Sample Survey and Registry data. BMJ Open. 2019;9(4):e025979. https://doi.org/10.1136/bmjopen-2018-025979.PMID: 31133622;PMCID:PMC6549895.

37. Sangar S, Dutt $V$, Thakur R. Burden of out-of-pocket health expenditure and its impoverishment impact in India: evidence from National Sample Survey. J Asian Public Policy. 2022;15(1):60-77.

38. Balarajan Y, Selvaraj S, Subramanian SV. Health care and equity in India. The Lancet. 2011;377(9764):505-15.

39. Mishra S, Mohanty SK. Out-of-pocket expenditure and distress financing on institutional delivery in India. Int J Equity Health. 2019;18(1):1-15.

40. Dasgupta P, Mukherjee S. Distress financing for out-of-pocket hospitalization expenses in India: An analysis of Pooled National Sample Survey Data. 2021.

41. Raghavendra RH. Literacy and health status of scheduled castes in India. Contemporary Voice of Dalit. 2020;12(1):97-110.

42. Ramaiah A. Health status of dalits in India. Econ Polit Wkly. 2015;50(43):70-4.

43. Perkins M, Brazier E, Themmen E, Bassane B, Diallo D, Mutunga A, Ngobola O. Out-of-pocket costs for facility-based maternity care in three African countries. Health Policy Plan. 2009;24(4):289-300.

44. Baird K. High out-of-pocket medical spending among the poor and elderly in nine developed countries. Health Serv Res. 2016;51(4):1467-88.

45. Ellis RP, Alam M, Gupta I. Health insurance in India: prognosis and prospectus. Econ Pol Wkly. 2000:207-17.

46. Panda P, Chakraborty A, Dror DM, Bedi AS. Enrolment in communitybased health insurance schemes in rural Bihar and Uttar Pradesh. India Health Policy and Planning. 2014;29(8):960-74.

47. Flores G, Krishnakumar J, O'Donnell O, Van Doorslaer E. Coping with healthcare costs: implications for the measurement of catastrophic expenditures and poverty. Health Econ. 2008;17(12):1393-412.

48. Hunter BM, Harrison S, Portela A, Bick D. The effects of cash transfers and vouchers on the use and quality of maternity care services: a systematic review. PloS One. 2017;12(3):e0173068.

\section{Publisher's Note}

Springer Nature remains neutral with regard to jurisdictional claims in published maps and institutional affiliations.

Ready to submit your research? Choose BMC and benefit from:

- fast, convenient online submission

- thorough peer review by experienced researchers in your field

- rapid publication on acceptance

- support for research data, including large and complex data types

- gold Open Access which fosters wider collaboration and increased citations

- maximum visibility for your research: over 100M website views per year

At BMC, research is always in progress.

Learn more biomedcentral.com/submissions 